Article

\title{
Persistence of HCV in Acutely-Infected Patients Depletes C24-Ceramide and Upregulates Sphingosine and Sphinganine Serum Levels
}

\author{
Georgios Grammatikos 1, 2,* Julia Dietz ${ }^{2}$, Nerea Ferreiros ${ }^{3}$, Alexander Koch ${ }^{1}$, Georg Dultz ${ }^{2}$, \\ Dimitra Bon ${ }^{4}$, Ioannis Karakasiliotis ${ }^{5}$, Thomas Lutz ${ }^{6}$, Gaby Knecht ${ }^{6}$, Peter Gute ${ }^{6}$, \\ Eva Herrmann ${ }^{3}$, Stefan Zeuzem ${ }^{2}$, Penelope Mavromara 5,7, Christoph Sarrazin ${ }^{2}$ \\ and Josef Pfeilschifter ${ }^{1}$ \\ 1 Pharmazentrum Frankfurt, Institut für Allgemeine Pharmakologie, Goethe University Hospital, \\ Frankfurt am Main, Theodor-Stern-Kai 7, 60590 Frankfurt am Main, Germany; \\ Koch@med.uni-frankfurt.de (A.K.); pfeilschifter@em.uni-frankfurt.de (J.P.) \\ 2 Medizinische Klinik 1, Goethe University Hospital, Frankfurt am Main, Theodor-Stern-Kai 7, \\ 60590 Frankfurt am Main, Germany; julia.dietz@em.uni-frankfurt.de (J.D.); georg.dultz@kgu.de (G.D.); \\ zeuzem@em.uni-frankfurt.de (S.Z.); sarrazin@em.uni-frankfurt.de (C.S.) \\ 3 Pharmazentrum Frankfurt, Institut für klinische Pharmakologie, Goethe University Hospital, \\ 60590 Frankfurt am Main, Germany; ferreirosbouzas@em.uni-frankfurt.de (N.F.); \\ Herrmann@med.uni-frankfurt.de (E.H.) \\ 4 Institute of Biostatistics and Mathematical Modelling, Department of Medicine, Goethe University, \\ 60590 Frankfurt am Main, Germany; bon@med.uni-frankfurt.de \\ 5 Molecular Virology, Hellenic Pasteur Institute, 11521 Athens, Greece; karakasiliotis@pasteur.gr (I.K.); \\ penelopm@pasteur.gr (P.M.) \\ 6 Infektiologikum, 60590 Frankfurt am Main, Germany; lutz@infektiologikum.de (T.L.); \\ knecht@infektiologikum.de (G.K.); gute@infektiologikum.de (P.G.) \\ 7 Molecular Biology and Genetics, Democritus University of Thrace, 68100 Alexandroupolis, Greece \\ * Correspondence: georgios.grammatikos@kgu.de; Tel.: +49-696-301-6963; Fax: +49-696-301-7942
}

Academic Editor: Johannes Haybaeck

Received: 14 May 2016; Accepted: 31 May 2016; Published: 13 June 2016

\begin{abstract}
Hepatitis C virus (HCV) substantially affects lipid metabolism, and remodeling of sphingolipids appears to be essential for HCV persistence in vitro. The aim of the current study is the evaluation of serum sphingolipid variations during acute $\mathrm{HCV}$ infection. We enrolled prospectively 60 consecutive patients with acute HCV infection, most of them already infected with human immunodeficiency virus (HIV), and serum was collected at the time of diagnosis and longitudinally over a six-month period until initiation of antiviral therapy or confirmed spontaneous clearance. Quantification of serum sphingolipids was performed by liquid chromatography-tandem mass spectrometry (LC-MS/MS). Spontaneous clearance was observed in 11 out of 60 patients (18.3\%), a sustained viral response (SVR) in 43 out of 45 patients (95.5\%) receiving an antiviral treatment after follow-up, whereas persistence of HCV occurred in six out of 60 patients $(10 \%)$. C24-ceramide (C24-Cer)-levels increased at follow-up in patients with spontaneous HCV eradication $(p<0.01)$, as compared to baseline. Sphingosine and sphinganine values were significantly upregulated in patients unable to clear HCV over time compared to patients with spontaneous clearance of HCV infection on follow-up ( $p=0.013$ and 0.006 , respectively). In summary, the persistence of HCV after acute infection induces a downregulation of $\mathrm{C} 24 \mathrm{Cer}$ and a simultaneous elevation of serum sphingosine and sphinganine concentrations.
\end{abstract}

Keywords: HIV; hepatitis C; sphingolipid; biomarker; angiopoietin-like 3 (ANGPTL3) 


\section{Introduction}

Acute infection with hepatitis $\mathrm{C}$ virus (HCV) remains in most cases clinically asymptomatic. The persistence of HCV occurs in approximately $75 \%$ of cases [1], and recent studies observed an epidemic transmission of HCV in injecting drug users (IDU) and in men having sex with men (MSM), mostly on the background of a chronic infection with human immunodeficiency virus (HIV) [2]. Since clinical management of acute HCV infection is still a matter of debate despite the availability of direct-acting antivirals (DAAs), the prediction of potential spontaneous clearance and identification of the optimal time point for therapeutic intervention require further insights into translational modifications occurring during acute HCV infection.

Numerous basic research studies highlighted the dependence of HCV on host lipid metabolism [3-6]. Particularly, sphingolipids (SLs), a diverse complex class of sphingosine-derived lipids with pleiotropic effects on the pathogenesis of various diseases, have been shown to affect replication and persistence of HCV in vitro [7-9]. Especially ceramide (Cer), the hydrophobic and functional backbone of SLs, alters the biophysical properties of biological membranes [10] and, thus, regulates the entry and replication of HCV in the host cell [11,12]. NS5B polymerase, which is crucial for HCV replication, possesses a sphingomyelin binding domain [13] and is critically affected by SL-regulated lipid peroxidation [14]. Additionally, inhibition of enzymes regulating the SL metabolism modifies the replication of HCV in vitro [14]. Yet, the interaction of HCV with lipids appears to be reciprocal, since chronic HCV infection is known to induce hypocholesterolemia [15]. Moreover, the expression of angiopoietin-like 3 (ANGPTL3), a liver-secreted protein able to affect serum lipid concentrations by regulation of serum lipases [16], was also shown to be negatively regulated by HCV [17]. HCV infection modulates ANGPTL3 levels by repression of hepatic nuclear factor (HNF) $1 \alpha$ [17], which is itself downregulated by Cer [18]. Yet, a direct interaction between ANGPTL3 and SLs has not been described so far. Regarding the role of lipids as potential biomarkers, serum lipids and apolipoproteins correlate with the efficiency of antiviral treatment $[19,20]$, and plasma apolipoprotein $\mathrm{H}$ levels are associated with spontaneous clearance of HCV during acute infection [21].

In our own, recent studies, we identified significant translational variations of the SL profile in chronic HCV infection. Particularly in the serum of patients chronically infected with HCV, we observed a significant upregulation of secreted acid sphingomyelinase activity [22]. Furthermore, chronic HCV infection induced a marked downregulation of C24Cer [22], and low C24Cer levels were in consecutive studies associated with severe liver fibrosis and poor responsiveness to antiviral therapy [23], as well as with clinical deterioration of HCV-associated cirrhosis [24]. Further SL metabolites, such as dihydroceramides (DHCs), able to regulate autophagy [25], correlated in our observations with the levels of aminotransferases [23], while sphingosine and sphinganine were identified in a multivariate model as novel independent predictors of severe HCV fibrosis [23].

The purpose of the current study is therefore the evaluation of serum SL concentrations during acute $\mathrm{HCV}$ infection to identify potential variations of serum SL levels upon spontaneous clearance or persistence of HCV. We further assessed potential correlations of ANGPTL3 levels to the outcome of acute $\mathrm{HCV}$ infection, and we also compared SL metabolite variations to already identified predictors of spontaneous clearance of HCV, such as the interleukin 28B (IL28B) genotype, HCV viral load, HCV genotype and to common biochemical markers in acutely-infected patients.

\section{Results}

\subsection{Patient Characteristics}

In the present prospective, study 60 consecutive patients with acute HCV infection were enrolled as mentioned above. The majority of patients were male (93.4\%), chronically infected with HIV (85\%) and acutely infected with HCV genotype 1 (73.4\%). Patient characteristics are demonstrated in Table 1. Our analysis focused on three different patient groups depending on the outcome of acute HCV infection. Group A included patients with spontaneous clearance of acute HCV infection; Group B 
included patients who received antiviral treatment; and Group C included patients with persistence of HCV. Spontaneous clearance was observed in 11 out of 60 patients (18.3\%), and 43 out of 45 patients (95.5\%) receiving an antiviral treatment achieved an SVR. Forty of the treated patients received a combination of PEGylated (PEG)-interferon (IFN) and ribavirin (RBV) according to the respective clinical recommendations [26], while four patients received PEG-IFN-monotherapy, and one patient received PEG-IFN/RBV and telaprevir within an open label trial. The persistence of HCV infection was observed in six patients $(10 \%)$. Two of these patients showed a non-response on antiviral treatment, and four patients did not receive antiviral therapy due to insufficient adherence and non-compliance.

Table 1. Patient's baseline biochemical and virological characteristics.

\begin{tabular}{|c|c|}
\hline Parameters & Patients with Acute HCV Infection $(n=60)$ \\
\hline Age, years: mean (range) & $42(22-61)$ \\
\hline Sex, male, $n=(\%)$ & $56(93.4)$ \\
\hline Female, $n=(\%)$ & $4(6.6)$ \\
\hline ALT, IU/L, mean (range) & $505(28-2738)$ \\
\hline AST, IU/L, mean (range) & $242(21-1957)$ \\
\hline$\gamma \mathrm{GT}, \mathrm{IU} / \mathrm{L}$, mean (range) & $250(25-1064)$ \\
\hline Bilirubin, $\mathrm{mg} / \mathrm{dL}$, mean (range) & $1.0(0.2-13)$ \\
\hline Thrombocytes, cells $/ \mu \mathrm{L}$, mean (range) & $210(115-324)$ \\
\hline INR, mean (range) & $1.05(0.9-1.3)$ \\
\hline IL28B-rs12979860 genotype, (CC/non_CC, $n=(\%))$ & $26(43.4) / 34(56.6)$ \\
\hline \multicolumn{2}{|l|}{ HCV genotype } \\
\hline $1, n=$ & 44 \\
\hline $1 \mathrm{a}, n=$ & 39 \\
\hline $1 b, n=$ & 4 \\
\hline Subtype not determined, $n=$ & 1 \\
\hline $2, n=$ & 2 \\
\hline $3, n=$ & 3 \\
\hline $4, n=$ & 11 \\
\hline HCV viral load, IU/mL: mean (range) & $7.7 \times 10^{6}\left(15-\left(8.6 \times 10^{7}\right)\right)$ \\
\hline $\begin{array}{l}\text { Estimated duration between infection to diagnosis (weeks) *: mean } \\
\text { (range) }\end{array}$ & $7(1-20)$ \\
\hline Duration diagnosis to initiation of therapy (weeks): mean (range) & $14(3-33)$ \\
\hline Duration diagnosis to spontaneous clearance (weeks): mean (range) & $30(4-100)$ \\
\hline Spontaneous clearance, $n=(\%)$ & $11(18.3)$ \\
\hline Antiviral therapy of acute $\mathrm{HCV}, n=(\%)$ & $45(75)$ \\
\hline SVR, $n=(\%$ of follow-up completed $)$ & $43(95.5)$ \\
\hline Non-response, $n=$ ( $\%$ of follow-up completed $)$ & $2(4.5)$ \\
\hline Lost to follow-up, $n=$ & 1 (excluded from the study) \\
\hline Persistence of HCV infection: $n=(\%)$ & $6(10)$ \\
\hline HIV coinfection: $n=(\%)$ & $51(85)$ \\
\hline Patients on ART: $n=(\%)$ & $38(74.5)$ \\
\hline CD4 count, cells $/ \mu \mathrm{L}:$ mean (range) & $561(207-1561)$ \\
\hline HIV patients with $<50$ copies $/ \mathrm{mL}: n=(\%$ of patients on ART $)$ & $32(62.7)$ \\
\hline
\end{tabular}

Abbreviations: ALT: alanine aminotransferase; AST: aspartate aminotransferase; $\gamma$ GT: $\gamma$-glutamyl-transferase; INR: international normalized ratio; IL: interleukin; HCV: hepatitis $C$ virus; HIV: human immunodeficiency virus; ART: antiretroviral therapy. ${ }^{*}$ The time point of acute hepatitis $C$ infection was determined according to the medical history or, if not applicable, the time point of infection was estimated by calculating the mean date between the last time point with normal aminotransferases and the first time point with a positive HCV RNA. Missing data: ALT levels were missing in 2 patients; AST levels were missing in 2 patients; $\gamma$ GT levels were missing in 2 patients; bilirubin levels were missing in 3 patients; thrombocyte levels were missing in 11 patients; INR levels were missing in 21 patients.

\subsection{Correlation of Serum Sphingolipids (SLs) with Hepatitis C Virus (HCV)/Human Immunodeficiency Virus} (HIV) Coinfection, Angiopoietin-Like 3 (ANGPTL3) and Biochemical Parameters

To evaluate the effect of HCV/HIV coinfection on the sphingolipidomic (SLomic) profile, we compared SL levels in HCV mono-infected and HCV/HIV co-infected patients at baseline. Except from a significant reduction of S1P levels in HCV / HIV coinfection $(p<0.01$, Figure 1D), no significant differences in the levels of further SL metabolites were observed among mono- and co-infected patients, both at baseline, as well as at follow-up (Figure 1, Supplementary Figures S1-S5). When common 
biochemical markers were compared to SL concentrations, the levels of Cer and DHC species correlated to the levels of transaminases, whereas solely S1P showed a significant inverse correlation to HCV viral load (Supplementary Table S1). Moreover, the evaluation of ANGPTL3 levels, a liver-secreted protein able to affect serum lipid concentrations, revealed neither an association with outcome of acute HCV infection (Supplementary Figure S6) nor a correlation with serum SL concentrations, apart from a weak positive association with C18Cer levels (Supplementary Table S1).
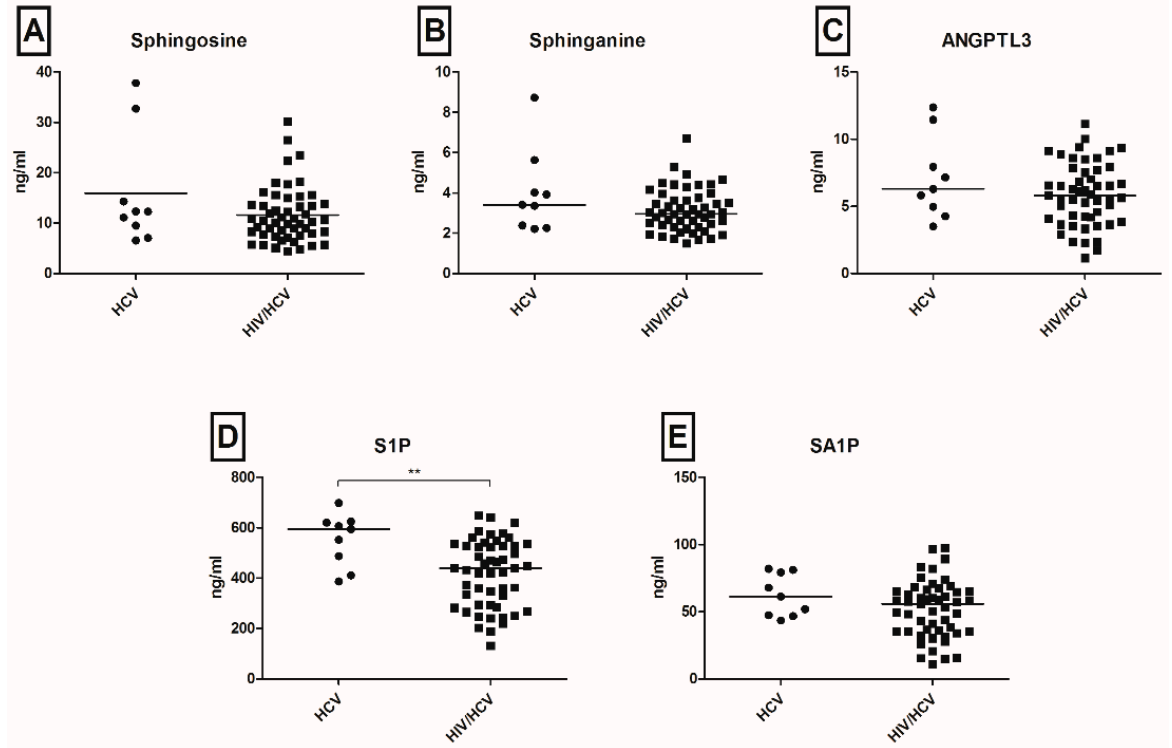

Figure 1. Serum sphingolipids (SLs) and angiopoietin-Like 3 (ANGPTL3) in hepatitis C virus (HCV)-mono-infection and in $\mathrm{HCV} /$ human immunodeficiency virus (HIV)-coinfection at baseline. $\mathrm{S} 1 \mathrm{P}$ levels in $\mathrm{HCV} / \mathrm{HIV}$-coinfected patients were lower than in HCV-mono-infected patients ((D), ** $p<0.01)$ at baseline. No significant differences in the levels of further SL metabolites $(\mathbf{A}, \mathbf{B}, \mathbf{E})$ and ANGPTL3 (C) were observed among mono- and co-infected patients. S1P: sphingosine 1-phosphate; SA1P: sphinganine 1-phosphate; ANGPTL3: angiopoietin-like 3.

\subsection{Spontaneous Clearance of HCV Restores Serum C24-Ceramide (C24-Cer) Levels}

Serum levels of DHCs and Cers with distinct fatty acid chain lengths were assessed in the patient cohort. Variations of serum SL metabolites were evaluated both among different outcomes (persistence and spontaneous or therapy-induced clearance of HCV), as well as longitudinally between baseline and follow-up for each outcome group. A significant increase in the levels of C24DHC and of its saturated derivative C24:1DHC was observed in patients with subsequent SVR after antiviral treatment in the longitudinal analysis (130 versus 162.1 and 160.9 versus $175.4 \mathrm{ng} / \mathrm{mL}$ between baseline and follow-up respectively, $p<0.01$; Figure 2). Further, the analysis of Cer species indicated that C16Cer, C20Cer and C24:1Cer levels increased longitudinally in patients with subsequent SVR after antiviral therapy $(p<0.001, p<0.05$ and $p<0.05$, respectively; Figure 3). C24Cer levels increased significantly during the course of acute infection in patients with spontaneous clearance $(p<0.01)$ or subsequent SVR after antiviral therapy $(p<0.05)$, while no differences were observed in patients with persistence of the virus (Figure 3D). 

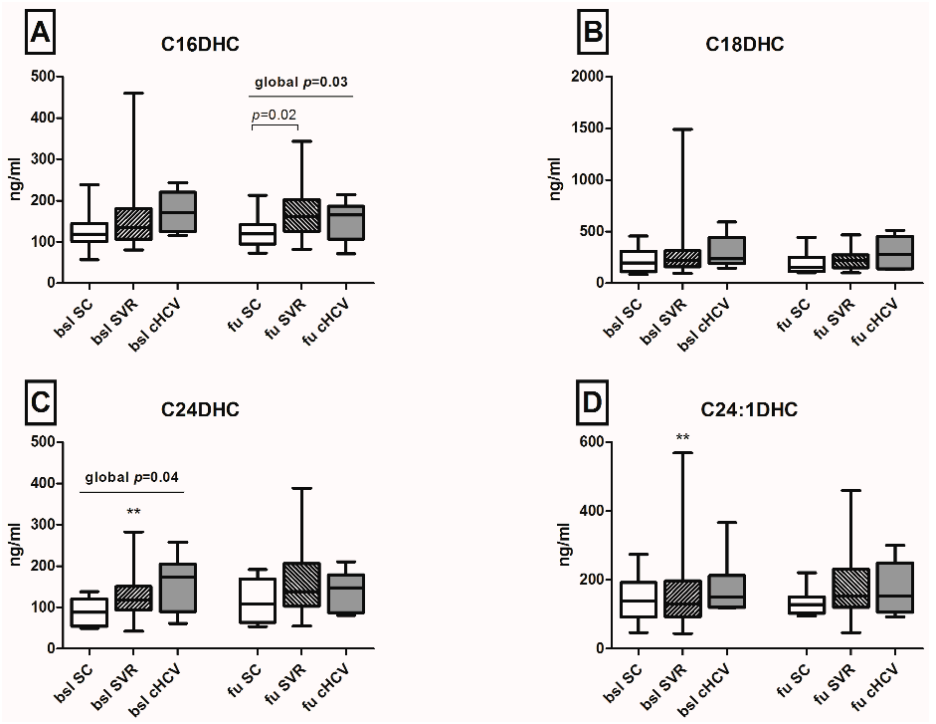

Figure 2. Serum dihydroceramide concentrations during acute HCV infection. C16DHC levels on follow-up were significantly lower in patients with spontaneous HCV clearance ((A), $p=0.02)$, while levels of $\mathrm{C} 24 \mathrm{DHC}$ and of its saturated derivative $\mathrm{C} 24: 1 \mathrm{DHC}$ increased longitudinally in patients with subsequent SVR after antiviral treatment $\left((\mathbf{C}, \mathbf{D})\right.$, respectively, $\left.{ }^{* *} p<0.01\right)$. No significant variations of $\mathrm{C} 18 \mathrm{DHC}$ levels were observed both between patient groups and between baseline and follow-up (B). Statistical significance between baseline and follow-up is indicated by asterisks $\left(^{*}\right)$. DHC: dihydroceramide; SC: spontaneous clearance; SVR: sustained viral response; BSL: baseline; FU: follow-up; cHCV: chronic HCV.
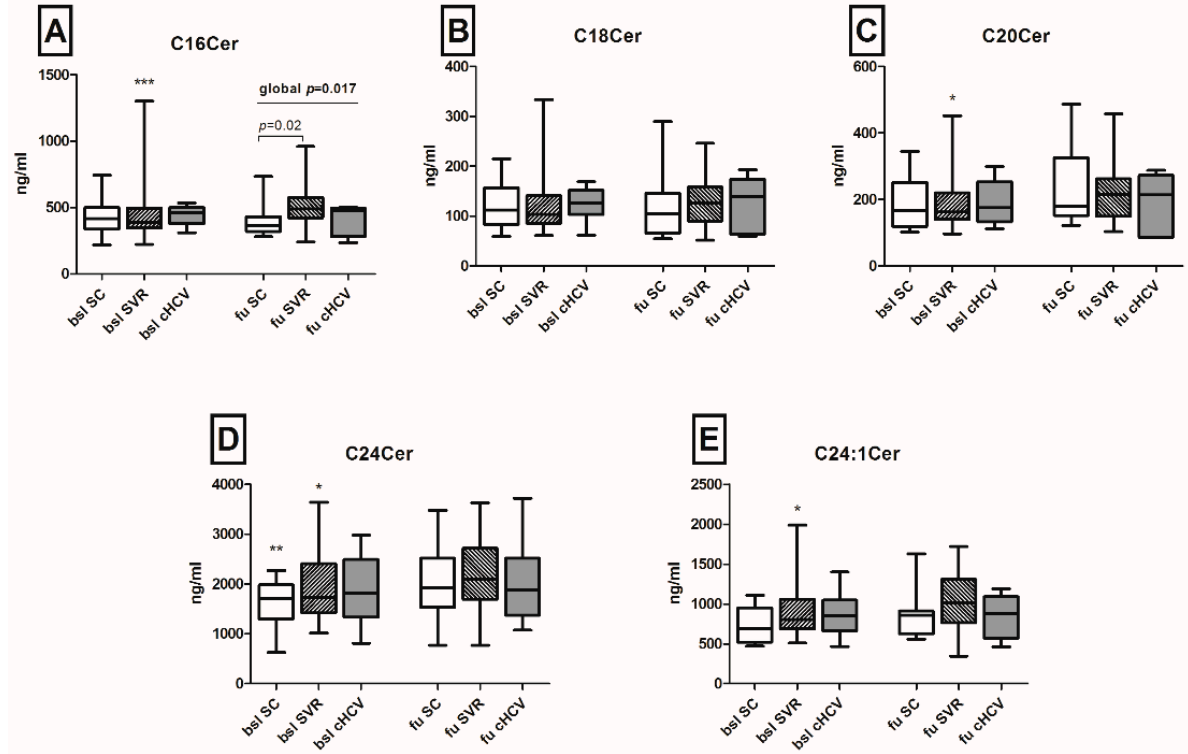

Figure 3. Serum ceramide variations during acute HCV infection. C16Cer, C18Cer, C20Cer, C24Cer and C24:1Cer levels increased during the course of untreated acute HCV infection in patients with subsequent SVR after antiviral therapy $((\mathbf{A}) * * * * 0.001,(\mathbf{B})$ non-significant, $(\mathbf{C}) * p<0.05,(\mathbf{D}) * p<0.05$, ** $p<0.01$ and $(\mathbf{E}) * p<0.05$, respectively). C24Cer levels increased significantly during the course of acute infection also in patients with spontaneous clearance, as well ((D), $p<0.01)$, and on follow-up, C16Cer levels were significantly lower in patients with spontaneous HCV clearance as compared to patients with subsequent SVR $((\mathbf{A}), p=0.02)$. Statistical significance between baseline and follow-up is indicated by asterisks $\left.{ }^{*}\right)$. Cer: ceramide; SC: spontaneous clearance; SVR: sustained viral response; BSL: baseline; FU: follow-up; cHCV: chronic HCV. 


\subsection{Upregulation of Sphingosine and Sphinganine Levels upon the Persistence of HCV}

Sphingosine values were significantly upregulated in patients unable to clear HCV as compared both to patients with spontaneous $(p=0.013)$ or therapy-induced viral eradication $(p=0.02)$ of HCV at follow-up, while at baseline, no significant variations between the outcome groups were observed (Figure 4A). Similarly, sphinganine levels were significantly elevated upon chronification of HCV infection as compared to spontaneous clearance of the virus ( $p=0.006)$ (Figure 4B). Regarding the corresponding phosphates, patients with achieved SVR after subsequent antiviral treatment showed a significant longitudinal reduction of S1P levels ( $p<0.01$, Figure 4 C), while no significant variations in the levels of dhS1P were observed (Figure 4C).
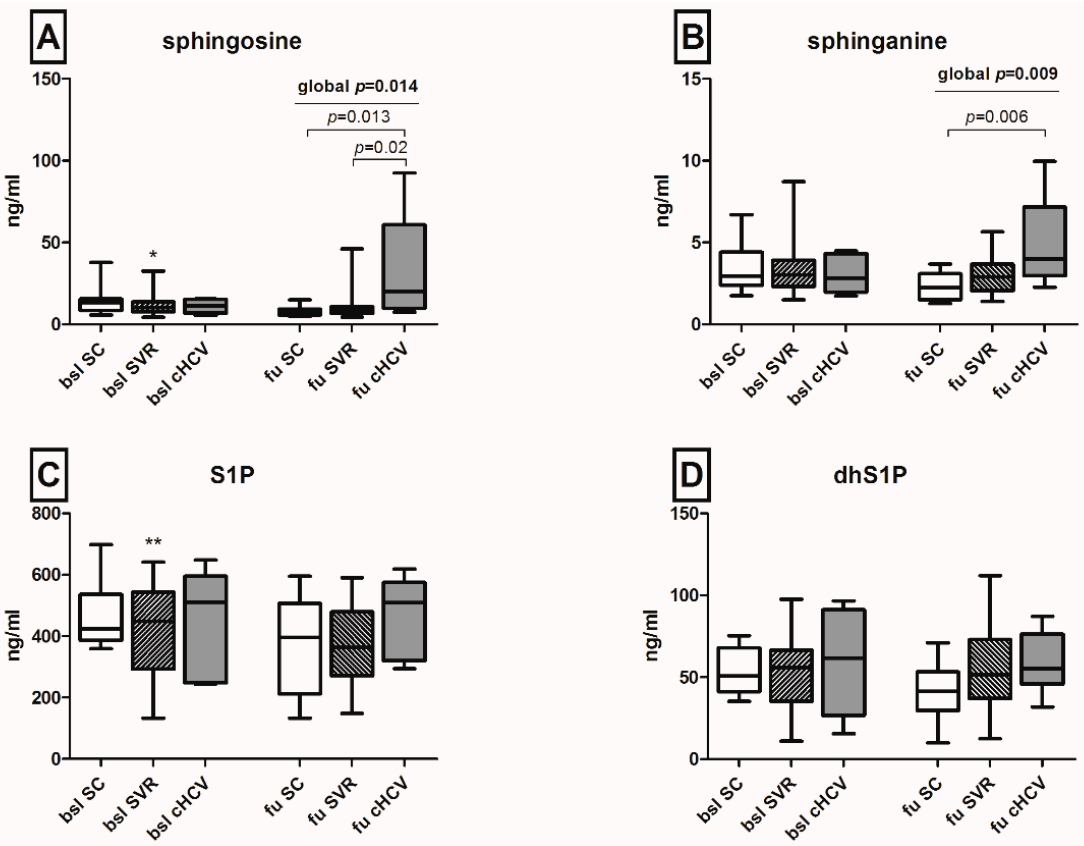

Figure 4. Sphingosine, sphinganine and their phosphate derivatives during acute HCV infection. Sphingosine levels on follow-up were significantly upregulated in patients unable to clear HCV compared both to patients with spontaneous or subsequent therapy-induced resolution of $\mathrm{HCV}$ infection ((A), $p=0.02$ and $p=0.013$, respectively). Sphinganine levels were significantly elevated upon chronification of HCV infection on follow-up $((\mathbf{B}), p=0.006)$, while patients with subsequent SVR after antiviral treatment showed a significant longitudinal reduction of S1P levels $\left.(\mathbf{C}),{ }^{* *} p<0.01\right)$. No significant difference in dhS1P levels was observed (D). Statistical significance between baseline and follow-up is indicated by asterisks $\left({ }^{*}\right)$. S1P: sphingosine 1 phosphate; dh: dihydro; SC: spontaneous clearance; SVR: sustained viral response; BSL: baseline; FU: follow-up; cHCV: chronic HCV.

\subsection{Univariate Analysis of Baseline Markers Associated with Spontaneous HCV Clearance}

To address the hypothesis of whether baseline SL concentrations are able to predict spontaneous clearance of $\mathrm{HCV}$, we performed a univariate analysis of baseline parameters in patients with spontaneous clearance and in patients with persistence of $\mathrm{HCV}$, as shown in Table 2. No significant differences between the two outcome groups were identified in the levels of aminotransferases, baseline viral load, bilirubin, thrombocytes, international normalized ratio (INR), as well as in the existence or not of an HIV-coinfection or of a favorable IL28B-rs12979860 CC genotype (Table 2). Adequate HIV treatment, represented by the proportion of patients with low HIV viral load and by the count of CD4 cells, did not affect significantly the spontaneous clearance of HCV infection, as well (Table 2). The HCV genotype 1 and high C24DHC levels were the only parameters where a trend and significance were observed in patients with persistence of $\mathrm{HCV}$ as compared to patients with spontaneous clearance of the virus ( $p=0.056$ and 0.047 , respectively). 
Table 2. Univariate analysis of baseline parameters associated with spontaneous clearance compared to HCV persistence.

\begin{tabular}{|c|c|c|c|}
\hline Parameters & $\begin{array}{l}\text { Spontaneous Clearance } \\
\qquad(n=11)\end{array}$ & Persistence of HCV $(n=6)$ & $p$-Value \\
\hline Age, years: mean (range) & $42(22-54)$ & $43.5(37-56)$ & 0.2 \\
\hline AST, IU/L: mean (range) & $224(51-745)$ & $132(33-402)$ & 0.1 \\
\hline$\gamma \mathrm{GT}, \mathrm{IU} / \mathrm{L}:$ mean (range) & $220(31-310)$ & $205.5(93-407)$ & 0.7 \\
\hline Bilirubin, mg/dL: mean (range) & $1.35(0.5-2.2)$ & $0.765(0.5-2.64)$ & 0.4 \\
\hline HCV genotype $(n=, 1 /$ non- 1$)$ & $6 / 5$ & $6 / 0$ & 0.056 \\
\hline HCV viral load, IU/mL: mean (range) & $1.4 \times 10^{6}\left(2780-\left(6.9 \times 10^{7}\right)\right)$ & $1.2 \times 10^{6}\left(64,900-\left(8.6 \times 10^{7}\right)\right)$ & 0.8 \\
\hline HIV coinfection: $(n=$, yes $/$ no $)$ & $8 / 3$ & $6 / 0$ & 0.1 \\
\hline HIV patients with $<50$ copies/mL: $(n=$, yes $/$ no $)$ & $5 / 3$ & $5 / 1$ & 0.4 \\
\hline CD4 count, cells $/ \mu \mathrm{L}$ : mean (range) & $564.7(312-850)$ & $480(207-766)$ & 0.5 \\
\hline C16DHC, ng/mL: mean (range) & $119(57.1-239)$ & $171.5(116-244)$ & 0.07 \\
\hline Sphingosine, ng/mL: mean (range) & $13.3(5.7-37.8)$ & $11.1(5.5-15.6)$ & 0.6 \\
\hline Sphinganine, ng/mL: mean (range) & $2.96(1.75-6.71)$ & $2.83(1.74-4.49)$ & 0.6 \\
\hline $\mathrm{S} 1 \mathrm{P}, \mathrm{ng} / \mathrm{mL}:$ mean (range) & $424(359-698)$ & $511(244-648)$ & 0.8 \\
\hline dhS1P, ng/mL: mean (range) & $50.7(35.3-75.3)$ & $61.6(15.6-96.6)$ & 0.8 \\
\hline
\end{tabular}

Abbreviations: ALT: alanine aminotransferase; AST: aspartate aminotransferase; $\gamma \mathrm{GT}$ : $\gamma$-glutamyl-transferase; INR: international normalized ratio; IL: interleukin; HCV: hepatitis C virus; HIV: human immunodeficiency virus; DHC: dihydroceramide; Cer: ceramide; S1P: sphingosine 1-phosphate; dhS1P: dihydrosphingosine 1-phosphate. Missing data: bilirubin levels were missing in 1 patient with spontaneous clearance of HCV; thrombocyte levels were missing in 3 patients with spontaneous clearance of HCV; INR levels were missing in 3 patients with spontaneous clearance and 3 patients with persistence of $\mathrm{HCV}$.

\section{Discussion}

The pathogenesis and persistence of HCV infection are associated with modifications of the host lipid metabolism. Especially replication, particle assembly and exocytosis of HCV rely on SLs $[7,8,14]$, a diverse class of lipids affecting several signaling pathways. Recently, we identified significant alterations of the SLomic profile in patients with chronic HCV infection and observed critical associations to the stage of HCV-induced liver fibrosis and decompensation of HCV-induced cirrhosis [22-24]. However, no data are available so far concerning early translational modifications of serum SLs occurring during the course of acute HCV infection.

Since most of the patients of our cohort were co-infected with HIV and SLs offer the essential metabolic environment for HIV fusion [27], entry [28] and escape from the host immune system [29], we compared the SLomic profile in HCV mono-infection and in HCV/HIV coinfection in order to exclude variations of serum SLs due to HIV infection. Except from significantly lower S1P levels in HCV/HIV coinfection, HIV infection did not affect the SLomic profile. Similarly, we evaluated the serum levels of ANGPTL3, a lipase secreted by the liver, which has been shown to affect HCV pathophysiology in vitro [17], and tested for potential correlations to serum SL concentrations and to the outcome of acute HCV infection. Despite the potential cross-talk between ANPTL3 and SLs via the interaction with HNF1 $\alpha[17,18]$, in our current study, no significant associations were observed.

Interestingly, we observed in the present study a restoration of serum C24Cer levels in patients with spontaneous clearance or subsequent SVR after antiviral treatment, while the persistence of $\mathrm{HCV}$ maintained low levels of C24Cer in the respective patients. This finding is in line with our own recently published observations revealing a substantial translational implication of C24Cer in chronic $\mathrm{HCV}$ infection. Particularly, we have previously demonstrated that chronic HCV infection induces a marked downregulation of serum C24Cer concentrations [22] and low serum C24Cer levels are associated with severe liver fibrosis, poor responsiveness to antiviral therapy [23] and, in cirrhotic HCV patients with decompensation of liver cirrhosis, the occurrence of ascites and poor overall survival [24]. 
In the current study, while a significant increase of C24Cer levels was determined after spontaneous clearance of HCV (1631.4 at baseline versus $2052.8 \mathrm{ng} / \mathrm{mL}$ at follow-up, $p<0.01$ ), serum concentrations of C24Cer were altogether lower compared to C24Cer levels in patients with chronic HCV infection $(3280.4 \mathrm{ng} / \mathrm{mL})$ and in healthy probands $(4225.3 \mathrm{ng} / \mathrm{mL})$, as observed by our group in a previous study [22]. A prolonged follow-up of patients regarding their serologic C24Cer levels after eradication of HCV and further basic research studies are needed to clarify the significance of these observations.

From a mechanistic point of view, animal model studies have described a severe hepatopathy as a consequence of genetic depletion of Cer-synthase 2, an enzyme predominantly expressed in the hepatic and renal tissue synthesizing C22-C24Cers [30]. Loss of Cer-synthase 2 activity was also linked to the promotion of chronic oxidative stress due to disruption of the mitochondrial respiratory chain [31]. Since HCV persistence is well known to be tightly linked to the regulation of oxidative stress and lipid peroxidation $[14,32,33]$, the observed downregulation of C24Cer levels may constitute an additional link between viral persistence and SL-mediated regulation of oxidative stress by HCV. Furthermore, the ongoing characterization of distinct functions of Cers according to the length of the fatty acid attached to the sphingosine backbone has attributed pro-proliferative effects to C24Cer in contrast to the anti-proliferative effects of Cers with a shorter fatty acid chain [34]. Thus, HCV-induced liver injury due to direct cytopathic effects mediated by the virus through perturbation of the cell cycle [35] could also be partially induced by the ablation of C24Cer levels. In this context, we additionally identified an inverse correlation between bilirubin, AST and C24Cer in our patient cohort. Thus, our findings confirm the aforementioned observations of in vitro studies and offer valuable insights into early modifications of the SL metabolism during acute HCV infection on a translational level. Additional studies are needed to unravel the mechanistic background of these observations.

Further insights into the regulatory role of SLs in HCV infection have been recently provided by Yamane $e t$ al., who identified a critical involvement of sphingosine-kinases in the replication process of HCV in vitro [14]. Inhibitors of regulatory SL enzymes induced an abrogation of HCV replication, while supplementation of the infectious $\mathrm{HCV}$ in cell culture (HCV $\mathrm{Cc}$ ) in vitro model with sphingosine and sphinganine, but not with S1P, promoted the replication of HCV strains [14]. In our current study, we observed a significant elevation of both sphingosine and sphinganine in patients with HCV persistence, as compared to spontaneous or therapy-induced clearance of the virus at follow-up. Since sphingosine has been long known to promote apoptosis and autophagy [36] and the occurrence of a severe hepatopathy in CerS2-knockout mice has been shown to correlate significantly with elevated sphinganine levels [30], both sphingosine and sphinganine may play a pivotal role in HCV-induced hepatopathy. Our observations on the upregulation of sphingosine and sphinganine six months after initial contact with the virus principally underline the early involvement of SLs in the process of HCV persistence and emphasize the potential utility of sphingosine and sphinganine as possible markers for the persistence of HCV during acute infection.

Although offering promising results, our study has some limitations. Due to the clinically unapparent course of acute HCV infection, only a moderate cohort size was included. Moreover, serum SL concentrations prior to acute HCV infection were missing, and further SLs, such as sphingomyelin, were not available in our current analysis and could thus not be included in the interpretation of our observations. Furthermore, the well-established translational link between insulin resistance and both HIV infection [37], as well as responsiveness to antiviral therapy in chronic HCV infection [38] implies a major role for insulin resistance in HIV/HCV coinfected patients. Additionally, serum sphingolipids have been shown to reflect insulin resistance in patients under physical exercise [39]. Unfortunately, data on insulin resistance were lacking in our patient cohort. In spite of these limitations, our results offer a significant advance over previous studies.

\section{Experimental Section}

\subsection{Patients with Acute HCV Infection}

In a prospective study, blood was collected from 60 consecutive patients with an acute HCV infection. Most patients were coinfected with HIV (51 out of 60, confirmed by a positive HIV 
antibody test), while 9 out of 60 patients were mono-infected with HCV. Diagnosis was performed at the University Hospital and the Infectious-Disease Medical Center (Infektiologikum) in Frankfurt am Main, Germany, between 2009 and 2013, as previously reported by our group [40]. Acute hepatitis $\mathrm{C}$ was in most cases diagnosed within the routine laboratory examination of HIV-infected patients, and diagnosis was defined by previously published criteria [41], such as the detection of HCV-RNA with or without concomitant positive anti-HCV antibodies in combination with a negative test for HCV-RNA or anti-HCV antibody in the last 12 months, as well as HCV-RNA positivity and elevation of the alanine aminotransferase (ALT) of more than 5-times the upper limit of the normal range and normal ALT within the last 12 months. Serum was collected at the time of diagnosis of acute HCV infection (termed as baseline) and longitudinally over a 6-month period until initiation of antiviral therapy or confirmed spontaneous clearance (termed as follow-up), as mentioned before [40]. The time point of acute hepatitis $C$ infection was determined according to the medical history of each patient or, if not applicable, the time point of infection was estimated by calculating the mean date between the last time point with normal aminotransferases and the first time point with a positive HCV-RNA, as mentioned before [40]. Spontaneous clearance was defined as negative HCV-RNA detected twice within an interval of at least 12 weeks without receiving antiviral therapy and confirmation 6 months after diagnosis of acute hepatitis C. Sustained virologic response (SVR) was determined by HCV-RNA negativity 12 weeks after the end-of-treatment. Chronic HCV infection was defined as the presence of HCV RNA 24 weeks after diagnosis without treatment. One patient was excluded from the study due to being lost to follow-up. The study was performed in accordance with the Declaration of Helsinki and was approved by the local ethics committee. All patients had signed a written informed consent before study inclusion.

\subsection{Determination of Sphingolipid Concentrations by High-Performance Liquid Chromatography Tandem Mass Spectrometry}

Quantification of serum SLs was performed by high-performance liquid chromatography-tandem mass spectrometry (LC-MS/MS, AB Sciex, Darmstadt, Germany), as previously described [23]. For quantitation of SLs, $20 \mu \mathrm{L}$ of serum were extracted with methanol/chloroform/ $\mathrm{HCl}$ (15:83:2).

Afterwards, amounts of C16:0Cer, C18:0Cer, C20:0Cer, C24:0Cer, C24:1Cer, C16:0DHC, $\mathrm{C} 18: 0 \mathrm{DHC}, \mathrm{C} 24: 0 \mathrm{DHC}, \mathrm{C} 24: 1 \mathrm{DHC}$ and the internal standard (C17:0Cer) and sphingosine, sphingosine 1-phosphate (S1P) and sphinganine 1-phopshate (dhS1P) and the internal standards (sphingosine-D7, sphinganine-D7 and sphingosine 1-phosphate-D7) were analyzed by LC-MS/MS. All serum samples were stored at $-80{ }^{\circ} \mathrm{C}$ until assayed. Further details on the mass spectrometric quantification of sphingolipids are provided in the Supplementary Material.

\subsection{Detection of ANGTL3 Serum Concentrations}

ANGPTL3 serum levels were determined by using the ANGPTL-3 ELISA kit (Adipogen AG, Liestal, Switzerland) according to the manufacturer's instructions, as previously described [17].

\subsection{Statistical Analysis}

Statistical analysis for the scatter and box plots presented was performed with GraphPad Prism for Windows (v5.01; GraphPad Software Inc., San Diego, CA, USA). We carried out statistical analyses of the data using the BIAS software (BIAS for Windows, Version 10.11, Epsilon-Verlag, Darmstadt, Germany). Statistical comparisons for continuous variables with the outcome of acute hepatitis $C$ were performed using the Wilcoxon-Mann-Whitney $U$-test (comparison of 2 groups) or the Kruskal-Wallis test (comparison of 3 or more groups). Dichotomic variables were assessed by means of contingency tables (Mantel-Haenszel's test), as appropriate. The data are expressed as means \pm standard error, unless otherwise specified. For statistical differences within the same group of patients over distinct time points, the Wilcoxon matched pairs test was applied. The level of significance was set at $\alpha=0.05$, representing the $95 \%$ confidence interval $(\mathrm{CI})$. Statistically-significant differences are indicated in the corresponding figures $\left({ }^{*} p<0.05 ;{ }^{* *} p<0.01{ }^{* * *} p<0.001\right.$ ). 


\section{Conclusions}

In conclusion, our study emphasizes the potential of serum SLomics as a promising approach to identify novel biomarkers of acute HCV infection. Particularly, the serologic determination of C24Cer, sphingosine and sphinganine during the first months of acute HCV infection may contribute to the correct identification of patients being at a higher risk for developing a chronic infection and, thus, suitable for early initiation of antiviral therapy. Further prospective studies on the SL profile of the host during acute HCV infection are required for the implementation of SLs as biomarkers for clinical decision making.

Supplementary Materials: Supplementary materials can be found at http://www.mdpi.com/1422-0067/17/6/ 922/s1.

Acknowledgments: We would like to thank Caterina Berkowski and Yannick Schreiber for excellent technical assistance. This work was supported by the German Research Foundation DFG by grants (SFB 1039) awarded to Georgios Grammatikos and Josef Pfeilschifter.

Author Contributions: Conceived of and designed the experiments: Georgios Grammatikos, Nerea Ferreiròs, Penelope Mavromara, Alexander Koch, Stefan Zeuzem, Christoph Sarrazin, Josef Pfeilschifter. Performed the experiments: Georgios Grammatikos, Alexander Koch, Nerea Ferreiròs. Analyzed the data: Georgios Grammatikos, Nerea Ferreiròs, Dimitra Bon, Eva Herrmann, Christoph Sarrazin, Stefan Zeuzem, Josef Pfeilschifter. Contributed reagents/materials/analysis tools: Georgios Grammatikos, Julia Dietz, Georg Dultz, Alexander Koch, Nerea Ferreiròs, Ioannis Karakasiliotis, Penelope Mavromara, Thomas Lutz, Gaby Knecht, Peter Gute. Wrote the paper: Georgios Grammatikos, Eva Herrmann, Stefan Zeuzem, Christoph Sarrazin, Josef Pfeilschifter.

Conflicts of Interest: The authors declare no conflict of interest.

$\begin{array}{ll}\text { Abbreviations } & \\ \text { HCV } & \text { hepatitis C virus } \\ \text { IDU } & \text { injecting drug users } \\ \text { MSM } & \text { men having sex with men } \\ \text { HIV } & \text { human immunodeficiency virus } \\ \text { DAA } & \text { direct-acting antiviral } \\ \text { SL } & \text { sphingolipid } \\ \text { ANGPTL3 } & \text { angiopoietin-like 3 } \\ \text { Cer } & \text { ceramide } \\ \text { DHC } & \text { dihydroceramide } \\ \text { ALT } & \text { alanine aminotransferase } \\ \text { SVR } & \text { sustained viral response } \\ \text { LC-MS/MS } & \text { liquid chromatography-tandem mass spectrometry } \\ \text { S1P } & \text { sphingosine 1-phosphate } \\ \text { dhS1P } & \text { sphinganine 1-phosphate } \\ \text { APCI } & \text { atmospheric pressure chemical ionization } \\ \text { ESI } & \text { electrospray ionization } \\ \text { MRM } & \text { multiple reaction monitoring } \\ \text { CI } & \text { confidence interval } \\ \text { PEG-IFN } & \text { PEGylated interferon } \\ \text { RBV } & \text { ribavirin } \\ \text { INR } & \text { international normalized ratio }\end{array}$

\section{References}

1. Hajarizadeh, B.; Grebely, J.; Dore, G.J. Epidemiology and natural history of HCV infection. Nat. Rev. Gastroenterol. Hepatol. 2013, 10, 553-562. [CrossRef] [PubMed]

2. Hullegie, S.J.; Arends, J.E.; Rijnders, B.J.; Irving, W.L.; Salmon, D.; Prins, M.; Wensing, A.M.; Klenerman, P.; Leblebicioglu, H.; Boesecke, C.; et al. Current knowledge and future perspectives on acute hepatitis C infection. Clin. Microbiol. Infect. 2015, 21, 797. [CrossRef] [PubMed]

3. Miyanari, Y.; Atsuzawa, K.; Usuda, N.; Watashi, K.; Hishiki, T.; Zayas, M.; Bartenschlager, R.; Wakita, T.; Hijikata, M.; Shimotohno, K. The lipid droplet is an important organelle for hepatitis $\mathrm{C}$ virus production. Nat. Cell Biol. 2007, 9, 1089-1097. [CrossRef] [PubMed]

4. Shi, S.T.; Lee, K.J.; Aizaki, H.; Hwang, S.B.; Lai, M.M. Hepatitis C virus RNA replication occurs on a detergent-resistant membrane that cofractionates with caveolin-2. J. Virol. 2003, 77, 4160-4168. [CrossRef] [PubMed] 
5. Saxena, V.; Lai, C.K.; Chao, T.C.; Jeng, K.S.; Lai, M.M. Annexin A2 is involved in the formation of hepatitis C virus replication complex on the lipid raft. J. Virol. 2012, 86, 4139-4150. [CrossRef] [PubMed]

6. Jiang, J.; Luo, G. Apolipoprotein E but not B is required for the formation of infectious hepatitis $\mathrm{C}$ virus particles. J. Virol. 2009, 83, 12680-12691. [CrossRef] [PubMed]

7. Aizaki, H.; Morikawa, K.; Fukasawa, M.; Hara, H.; Inoue, Y.; Tani, H.; Saito, K.; Nishijima, M.; Hanada, K.; Matsuura, Y.; Lai, M.M.C.; et al. Critical role of virion-associated cholesterol and sphingolipid in hepatitis C virus infection 2. J. Virol. 2008, 82, 5715-5724. [CrossRef] [PubMed]

8. Hirata, Y.; Ikeda, K.; Sudoh, M.; Tokunaga, Y.; Suzuki, A.; Weng, L.; Ohta, M.; Tobita, Y.; Okano, K.; Ozeki, K.; et al. Self-enhancement of hepatitis C virus replication by promotion of specific sphingolipid biosynthesis 1. PLoS Pathog. 2012, 8, e1002860. [CrossRef] [PubMed]

9. Sakamoto, H.; Okamoto, K.; Aoki, M.; Kato, H.; Katsume, A.; Ohta, A.; Tsukuda, T.; Shimma, N.; Aoki, Y.; Arisawa, M.; et al. Host sphingolipid biosynthesis as a target for hepatitis C virus therapy 2. Nat. Chem. Biol. 2005, 1, 333-337. [CrossRef] [PubMed]

10. Simons, K.; Ikonen, E. Functional rafts in cell membranes. Nature 1997, 387, 569-572. [CrossRef] [PubMed]

11. Aizaki, H.; Lee, K.J.; Sung, V.M.; Ishiko, H.; Lai, M.M. Characterization of the hepatitis C virus RNA replication complex associated with lipid rafts. Virology 2004, 324, 450-461. [CrossRef] [PubMed]

12. Voisset, C.; Lavie, M.; Helle, F.; Op de, B.A.; Bilheu, A.; Bertrand-Michel, J.; Tercé, F.; Cocquerel, L.; Wychowski, C.; Vu-Dac, N.; et al. Ceramide enrichment of the plasma membrane induces CD81 internalization and inhibits hepatitis C virus entry. Cell Microbiol. 2008, 10, 606-617. [CrossRef] [PubMed]

13. Weng, L.; Hirata, Y.; Arai, M.; Kohara, M.; Wakita, T.; Watashi, K.; Shimotohno, K.; He, Y.; Zhong, J.; Toyoda, T. Sphingomyelin activates hepatitis C virus RNA polymerase in a genotype-specific manner. J. Virol. 2010, 84, 11761-11770. [CrossRef] [PubMed]

14. Yamane, D.; McGivern, D.R.; Wauthier, E.; Yi, M.; Madden, V.J.; Welsch, C.; Antes, I.; Wen, Y.; Chugh, P.E.; McGee, C.E.; et al. Regulation of the hepatitis C virus RNA replicase by endogenous lipid peroxidation 1. Nat. Med. 2014, 20, 927-935. [CrossRef] [PubMed]

15. Corey, K.E.; Kane, E.; Munroe, C.; Barlow, L.L.; Zheng, H.; Chung, R.T. Hepatitis C virus infection and its clearance alter circulating lipids: Implications for long-term follow-up. Hepatology 2009, 50, 1030-1037. [CrossRef] [PubMed]

16. Shimizugawa, T.; Ono, M.; Shimamura, M.; Yoshida, K.; Ando, Y.; Koishi, R.; Ueda, K.; Inaba, T.; Minekura, H.; Kohama, T.; et al. ANGPTL3 decreases very low density lipoprotein triglyceride clearance by inhibition of lipoprotein lipase. J. Biol. Chem. 2002, 277, 33742-33748. [CrossRef] [PubMed]

17. Foka, P.; Karamichali, E.; Dalagiorgou, G.; Serti, E.; Doumba, P.P.; Pissas, G.; Kakkanas, A.2.; Kazazi, D.; Kochlios, E.; Gaitanou, M.; et al. Hepatitis C virus modulates lipid regulatory factor Angiopoietin-like 3 gene expression by repressing HNF-1 $\alpha$ activity 1. J. Hepatol. 2014, 60, 30-38. [CrossRef] [PubMed]

18. Park, I.N.; Cho, I.J.; Kim, S.G. Ceramide negatively regulates glutathione S-transferase gene transactivation via repression of hepatic nuclear factor-1 that is degraded by the ubiquitin proteasome system 2 . Mol. Pharmacol. 2004, 65, 1475-1484. [CrossRef] [PubMed]

19. Ramcharran, D.; Wahed, A.S.; Conjeevaram, H.S.; Evans, R.W.; Wang, T.; Belle, S.H.; Yee, L.J.; Virahep-C Study Group. Associations between serum lipids and hepatitis $C$ antiviral treatment efficacy. Hepatology 2010, 52, 854-863. [CrossRef] [PubMed]

20. Sultanik, P.; Mallet, V.; Lagaye, S.; Casrouge, A.; Dorival, C.; Barthe, Y.; Fontaine, H.; Hézode, C.; Mottez, E.; Bronowicki, J.P.; et al. Plasma apolipoprotein H limits HCV replication and associates with response to NS3 protease inhibitors-based therapy. Liver Int. 2015, 35, 1833-1844. [CrossRef] [PubMed]

21. Laird, M.E.; Mohsen, A.; Duffy, D.; Mamdouh, R.; LeFouler, L.; Casrouge, A.; El-Daly, M.; Rafik, M.; Abdel-Hamid, M.; Soulier, A.; et al. Apolipoprotein H expression is associated with IL28B genotype and viral clearance in hepatitis C virus infection. J. Hepatol. 2014, 61, 770-776. [CrossRef] [PubMed]

22. Grammatikos, G.; Muhle, C.; Ferreiros, N.; Schroeter, S.; Bogdanou, D.; Schwalm, S.; Hintereder, G.; Kornhuber, J.; Zeuzem, S.; Sarrazin, C.; et al. Serum acid sphingomyelinase is upregulated in chronic hepatitis C infection and non alcoholic fatty liver disease. Biochim. Biophys. Acta 2014, 1841, 1012-1020. [CrossRef] [PubMed]

23. Grammatikos, G.; Ferreiros, N.; Bon, D.; Schwalm, S.; Dietz, J.; Berkowski, C.; Fitting, D.; Herrmann, E.; Zeuzem, S.; Sarrazin, C.; et al. Variations in serum sphingolipid levels associate with liver fibrosis progression and poor treatment outcome in hepatitis C virus but not hepatitis B virus infection. Hepatology 2015, 61, 812-822. [CrossRef] [PubMed] 
24. Grammatikos, G.; Ferreiros, N.; Waidmann, O.; Bon, D.; Schroeter, S.; Koch, A.; Herrmann, E.; Zeuzem, S.; Kronenberger, B.; Pfeilschifter, J. Serum sphingolipid variations associate with hepatic decompensation and survival in patients with cirrhosis 1. PLoS ONE 2015, 10, e0138130. [CrossRef] [PubMed]

25. Signorelli, P.; Munoz-Olaya, J.M.; Gagliostro, V.; Casas, J.; Ghidoni, R.; Fabrias, G. Dihydroceramide intracellular increase in response to resveratrol treatment mediates autophagy in gastric cancer cells. Cancer Lett. 2009, 282, 238-243. [CrossRef] [PubMed]

26. Mutimer, D.; Aghemo, A.; Diepolder, H.; Negro, F.; Robaeys, G.; Ryder, S.; Zoulim, F. EASL Clinical Practice Guidelines: Management of hepatitis C virus infection. J. Hepatol. 2014, 60, 392-420.

27. Vieira, C.R.; Munoz-Olaya, J.M.; Sot, J.; Jimenez-Baranda, S.; Izquierdo-Useros, N.; Abad, J.L.; Apellániz, B.; Delgado, R.; Martinez-Picado, J.; Alonso, A.; et al. Dihydrosphingomyelin impairs HIV-1 infection by rigidifying liquid-ordered membrane domains. Chem. Biol. 2010, 17, 766-775. [CrossRef] [PubMed]

28. Hayashi, Y.; Nemoto-Sasaki, Y.; Tanikawa, T.; Oka, S.; Tsuchiya, K.; Zama, K.; Mitsutake, S.; Sugiura, T.; Yamashita, A. Sphingomyelin synthase 2, but not sphingomyelin synthase 1, is involved in HIV-1 envelope-mediated membrane fusion. J. Biol. Chem. 2014, 289, 30842-30856. [CrossRef] [PubMed]

29. Finnegan, C.M.; Rawat, S.S.; Puri, A.; Wang, J.M.; Ruscetti, F.W.; Blumenthal, R. Ceramide, a target for antiretroviral therapy. Proc. Natl. Acad. Sci. USA 2004, 101, 15452-15457. [CrossRef] [PubMed]

30. Pewzner-Jung, Y.; Brenner, O.; Braun, S.; Laviad, E.L.; Ben-Dor, S.; Feldmesser, E.; Horn-Saban, S.; Amann-Zalcenstein, D.; Raanan, C.; Berkutzki, T.; et al. A critical role for ceramide synthase 2 in liver homeostasis: II. insights into molecular changes leading to hepatopathy 2. J. Biol. Chem. 2010, 285, 10911-10923. [CrossRef] [PubMed]

31. Zigdon, H.; Kogot-Levin, A.; Park, J.W.; Goldschmidt, R.; Kelly, S.; Merrill, A.H., Jr.; Scherz, A.; Pewzner-Jung, Y.; Saada, A.; Futerman, A.H. Ablation of ceramide synthase 2 causes chronic oxidative stress due to disruption of the mitochondrial respiratory chain. J. Biol. Chem. 2013, 288, 4947-4956. [CrossRef] [PubMed]

32. Brault, C.; Levy, P.; Duponchel, S.; Michelet, M.; Salle, A.; Pecheur, E.I.; Plissonnier, M.L.; Parent, R.; Véricel, E.; Ivanov, A.V.; et al. Glutathione peroxidase 4 is reversibly induced by HCV to control lipid peroxidation and to increase virion infectivity1. Gut 2014, 65, 144-154. [CrossRef] [PubMed]

33. Farinati, F.; Cardin, R.; de, M.N.; Della, L.G.; Marafin, C.; Lecis, E. Iron storage, lipid peroxidation and glutathione turnover in chronic anti-HCV positive hepatitis 15. J. Hepatol. 1995, 22, 449-456. [CrossRef]

34. Grosch, S.; Schiffmann, S.; Geisslinger, G. Chain length-specific properties of ceramides. Prog. Lipid Res. 2012, 51, 50-62. [CrossRef] [PubMed]

35. Walters, K.A.; Syder, A.J.; Lederer, S.L.; Diamond, D.L.; Paeper, B.; Rice, C.M.; Katze, M.G. Genomic analysis reveals a potential role for cell cycle perturbation in HCV-mediated apoptosis of cultured hepatocytes. PLoS Pathog. 2009, 5, e1000269. [CrossRef] [PubMed]

36. Young, M.M.; Kester, M.; Wang, H.G. Sphingolipids: Regulators of crosstalk between apoptosis and autophagy. J. Lipid Res. 2013, 54, 5-19. [CrossRef] [PubMed]

37. Guillen, M.A.; Mejia, F.A.; Villena, J.; Turin, C.G.; Carcamo, C.P.; Ticse, R. Insulin resistance by homeostasis model assessment in HIV-infected patients on highly active antiretroviral therapy: Cross-sectional study. Diabetol. Metab. Syndr. 2015, 7, 49. [CrossRef] [PubMed]

38. Tarantino, G.; Conca, P.; Ariello, M.; Mastrolia, M. Does a lower insulin resistance affect antiviral therapy response in patients suffering from HCV related chronic hepatitis? Gut 2006, 55, 585. [PubMed]

39. Bergman, B.C.; Brozinick, J.T.; Strauss, A.; Bacon, S.; Kerege, A.; Bui, H.H.; Sanders, P.; Siddall, P.; Kuo, M.S.; Perreault, L. Serum sphingolipids: Relationships to insulin sensitivity and changes with exercise in humans. Am. J. Physiol. Endocrinol. Metab. 2015, 309, E398-E408. [CrossRef] [PubMed]

40. Dietz, J.; Lutz, T.; Knecht, G.; Gute, P.; Berkowski, C.; Lange, C.M.; Khaykin, P.; Stephan, C.; Brodt, H.R.; Herrmann, E.; et al. Evolution and function of the HCV NS3 protease in patients with acute hepatitis C and HIV coinfection 1. Virology 2015, 485, 213-222. [CrossRef] [PubMed]

41. Albert, M.; Benito, J.; Bhagani, S.; Boesecke, C.; Deterding, K.; Dominguez, S.; Fisher, M.; Fontanet, A.; Garcia, D.; Gilson, R.; et al. Acute hepatitis C in HIV-infected individuals: Recommendations from the European AIDS Treatment Network (NEAT) consensus conference. AIDS 2011, 25, 399-409.

(c) 2016 by the authors; licensee MDPI, Basel, Switzerland. This article is an open access article distributed under the terms and conditions of the Creative Commons Attribution (CC-BY) license (http://creativecommons.org/licenses/by/4.0/). 